Supporting Information

\title{
Label-Free Detection of C-T Mutations by Surface-Enhanced Raman Spectroscopy using Thiosulfate-Modified Nanoparticles
}

Jiayu Zeng, ${ }^{[a]}$ Meiyu Dong, ${ }^{[a]}$ Bixue Zhu, ${ }^{[a]}$ Xin Gao, ${ }^{[c]}$ Dongmei Chen ${ }^{*[a]}$ and Yang Li*[a][b]

${ }^{a}$ School of Chemistry and Chemical Engineering, Guizhou University, No. 2708, South Section of

Huaxi Avenue, Guiyang City, Guizhou Province, China.

${ }^{b}$ College of Pharmacy, Harbin Medical University, No. 157, Health Road, Nangang District, Harbin

City, Heilongjiang Province, China.

${ }^{c}$ School of Physics, Guizhou University, No. 2708, South Section of Huaxi Avenue, Guiyang City, Guizhou Province, China.

Corresponding Author: liy@hrbmu.edu.cn

\section{Table of Content}

S1. EXPERIMENTAL METHODS

S2.TEM OFAg@SCNPs S-3

S3. Ratio of the peak intensity of $I_{732} / I_{955}, I_{792} / I_{955}, I_{795} / I_{955}$ and $I_{655} / I_{955}$ in AT, AC, GC and GT.

S4. Histogram of $I_{A, C \& T \text { and } G} / I_{955}$ of the sequences Q, S, R, W, D and F. S-5

S5. The Raman peak assign to ssDNA S-6

S6. References. S-7 


\section{S1. EXPERIMENTAL METHODS}

\section{Ag@SCNPs preparation}

The Ag SCNPs was prepared based on our previous work. ${ }^{1}$ Briefly, $10 \mathrm{~mL}$ of sodium citrate-reduced silver sol was centrifuged $\left(5500 \mathrm{rpm}, 10 \mathrm{~min}, 15^{\circ} \mathrm{C}\right)$, after the removal of the supernatant, $20 \mu \mathrm{L}$ of the centrifuged silver sol was mixed with $25 \mu \mathrm{L}$ of Sodium thiosulfate solution $(1 \mathrm{mM})$ at room temperature for $24 \mathrm{~h}$. The reaction mixture was then cooled $4{ }^{\circ} \mathrm{C}$ (this was to ensure that the addition of single-stranded DNA sample for testing does not undergo changes in its structure, due to excessive temperature). After shaking to obtain a uniform system, the mixture was further mixed with $20 \mu \mathrm{L}$ DNA sample and $10 \mu \mathrm{L}$ of $\mathrm{Ca}^{2+}\left(0.01 \mathrm{M} \mathrm{CaCl}_{2}\right)$ one after another. After that, the mixture was shaken well for SERS detection. All DNA sequences (ssDNA) were analyzed at $1 \mu \mathrm{M}$ concentration throughout the SERS assay unless otherwise stated.

\section{Sample preparation for SERS}

DNA strands (HPLC grade) (Table S1)were purchased from Sangon Biotech (Shanghai) Co., Ltd. (Shanghai, China). $100 \mu \mathrm{M}$ DNA samples are annealed in $50 \mathrm{mM}$ ammonium acetate solution to form extension conformation by heating them in $90^{\circ} \mathrm{C}$ water bath for 5 minutes and self-folding followed by cooling down to room temperature. And then refrigerate overnight at minus four degrees Celsius. Ultra-pure water was used throughout the experiment. Raman spectra were carried out on WITec alpha300R confocal Raman microscopy (WITec GmbH). It operated at a laser (cobalt Laser) wavelength of $633 \mathrm{~nm}, 600 \mathrm{~g} / \mathrm{mm}$ grating, scanning time of 10 $\mathrm{s}$, with one accumulation, and laser power of $20 \mathrm{~mW}$. The SERS spectra obtained in this work did not use any smoothing operation, except for removing the base. The signals were eventually detected using a charge-coupled-device $(\mathrm{CCD})$ thermoelectrically cooled to $-60{ }^{\circ} \mathrm{C}$. The Raman data analysis are performed with WITec Project plus software. 


\section{S2. TEM OF Ag@SCNPs}

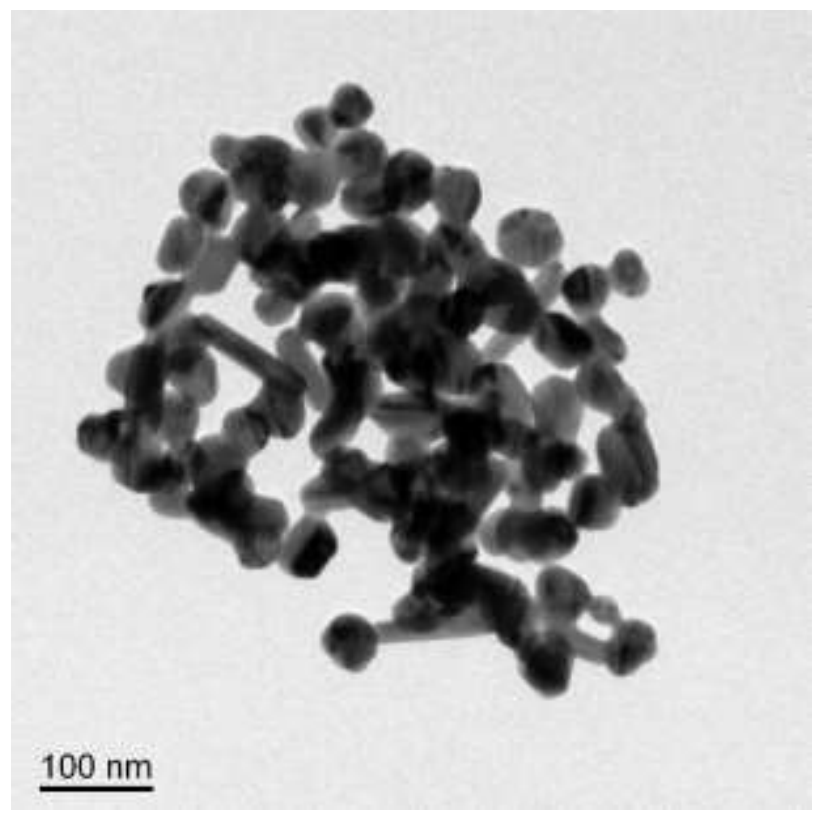

Figure S1 The transmission electron micrograph (TEM) of Ag@SCNPs 
S3. Ratio of the peak intensity of $I_{732} / I_{955}, I_{792} / I_{955}, I_{795} / I_{955}$ and $I_{655} / I_{955}$ in AT, AC, GC and GT.
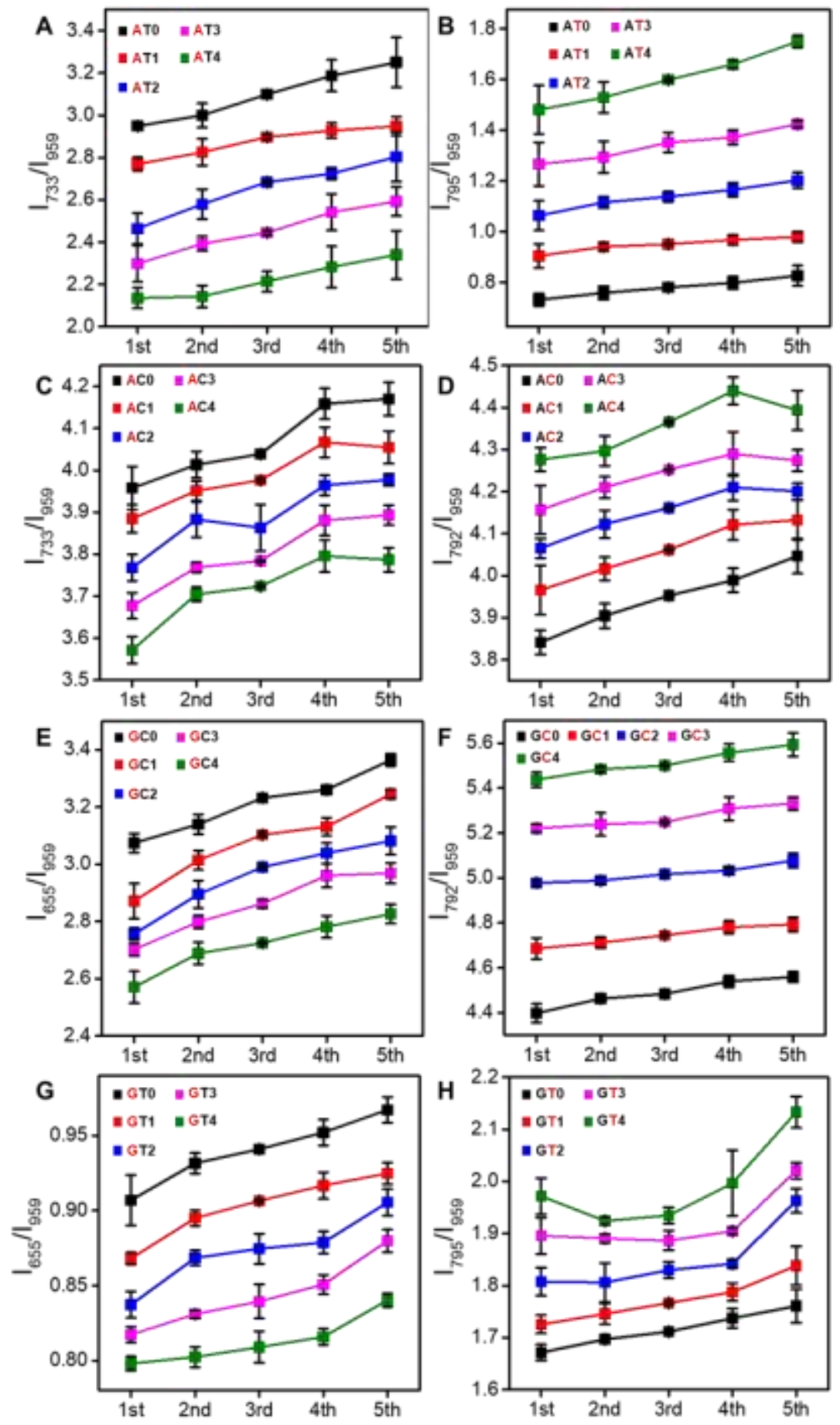

Figure S2 Ratio of the peak intensity of 732 (A)/959 $\mathrm{cm}^{-1}, 792(\mathrm{C}) / 959 \mathrm{~cm}^{-1}, 795(\mathrm{~T}) / 959 \mathrm{~cm}^{-1}$ and 655 (G)/959 $\mathrm{cm}^{-1}$ in (A, B) AT (0-4), (C, D) AC (0-4), (E, F) GC (0-4) and (G, H) GT (0-4) collected 5 times (1st-5th). Each data point represents an average of five measurements, and the error bar indicates the 
S4. Histogram of $I_{A, C \& T \text { and } G} / I_{955}$ of the sequences $Q, S, R, W$, $D$ and $F$.
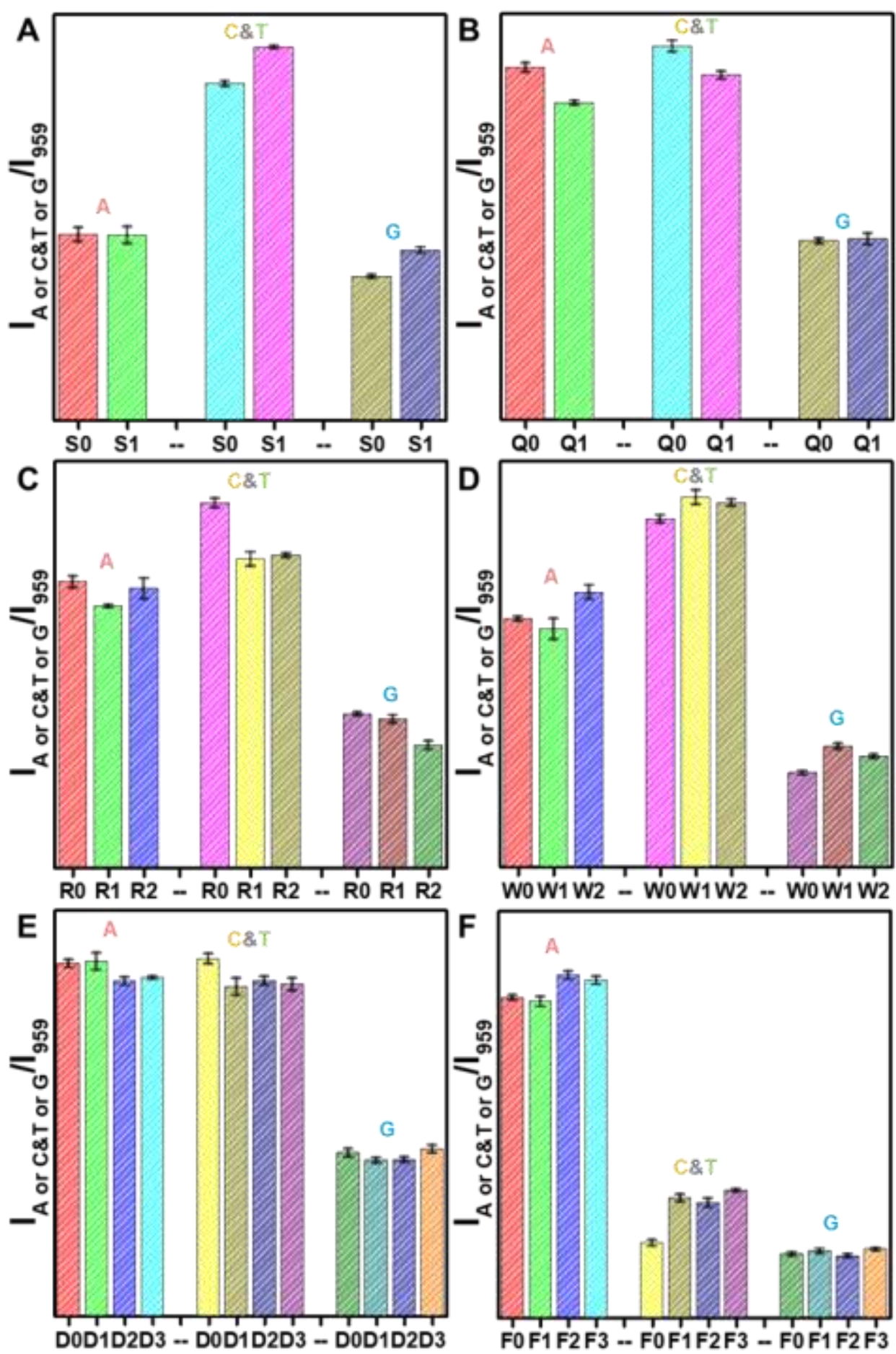

Figure S3 Ratio of the peak intensity of 733(A)/959 $\mathrm{cm}^{-1}, 791(\mathrm{C} \& \mathrm{~T}) / 959 \mathrm{~cm}^{-1}$ and 655 (G)/959 $\mathrm{cm}^{-1}$ in (A) $\mathrm{Q}(0-1)$, (B) $\mathrm{S}(0-1)$, (C) $\mathrm{R}(0-2)$, (D) GT(0-4), (E) $\mathrm{D}(0-3)$ and (F) $\mathrm{F}(0-3)$. Each data point represents an average of five measurements, and the error bar indicates the standard deviation. 


\section{S5. The Raman peak assign to ssDNA}

Table S1. The bands and their assignment appeared in the SERS spectra of ssDNA

\begin{tabular}{lll}
\hline Raman Shift/cm ${ }^{-1}$ & Assignment & Ref. \\
\hline 571 & dG & {$[2,3,4]$} \\
654 & dG R6 ring br & {$[2,3,5]$} \\
733 & dA & {$[3,4,5]$} \\
792 & dC & {$[3,4,5]$} \\
789 & dT & {$[3,4,5]$} \\
794 & $v_{\mathrm{s}}$ OPO & {$[2,4,5]$} \\
860 & $v$ OPO & {$[2,3,4]$} \\
929 & $\mathrm{~d}$ & {$[2,3,4]$} \\
955 & $\mathrm{~d}$ & {$[3,4,5]$} \\
1033 & $\mathrm{~d}(v$ C-O) & {$[3,4,5]$} \\
1089 & $v_{\mathrm{s}} \mathrm{PO}_{2}^{-}$ & {$[2,3,4]$} \\
1184 & $\mathrm{dT}$ & {$[1,2,4]$} \\
1251 & $\mathrm{dT}, \mathrm{dG}$ & {$[4,5]$} \\
1324 & $\mathrm{dG}$ & {$[3,4]$} \\
1650 & $\mathrm{dT}$ & {$[3,4,5]$} \\
\hline
\end{tabular}

Note: $\mathrm{d}=$ deoxyribose, $v=$ stretch, $\delta=$ deformation, $\mathrm{br}=$ breathing, $\mathrm{s}=$ symmetric, $\mathrm{s}=$ shoulder, $\mathrm{bk}=$ backbone. 


\section{S6. References}

\section{References}

[1] Li, Y.; Han, X.; Yan, Y.; Cao, Y.; Xiang, X.; Wang, S.; Zhao, B.; Guo, X. Label-Free Detection of Tetramolecular i-Motifs by Surface-Enhanced Raman Spectroscopy. Anal. Chem. 2018, 90 (5), 2996-3000.

[2] Deng, H.; Bloomfield, V. A.; Benevides, J. M.; Thomas, G. J. Dependence of the Raman signature of genomic B-DNA on nucleotide base sequence. Biopolymers 1999, 50, 656-666.

[3] Friedman, S. J.; Terentis, A. C. Friedman, S. J.; Terentis, A. C. Analysis of G-quadruplex conformations using Raman and polarized Raman spectroscopy. J. Raman Spectrosc. 2016, $47,259-268$.

[4] Krafft, C.; Benevides, J. M.; Jr, T. G. Secondary structure polymorphism in Oxytricha nova telomeric DNA. Nucleic Acids Res. 2002, 30, 3981-3991.

[5] Papadopoulou, E.; Bell, S. E. J. Label-Free Detection of Single-Base Mismatches in DNA by Surface-Enhanced Raman Spectroscopy. Angew. Chem. 2011, 123, 9224-9227. 